Contents lists available at Journal IICET

International Journal of Technology, Innovation and Humanities

ISSN: 2746-6434 (Electronic)

\title{
Development of alternative rear flickering light system
}

\author{
Mastura Ibrahim $^{1}$, Siti Aishah Wahid ${ }^{1}$, Sullyfaizura Mohd Rawi ${ }^{1}$ \\ ${ }^{1}$ Department of Mechanical Engineering, Politeknik Sultan Mizan Zainal Abidin, Malaysia
}

\begin{tabular}{l} 
Article Info \\
\hline Article history: \\
Received Sep 19th, 2020 \\
Revised Oct 12th, 2020 \\
Accepted Oct 27th, 2020 \\
\hline
\end{tabular}

\section{Keyword:}

Flickering Light

Arduino

vehicles

\begin{abstract}
The lighting system of a car consist of lighting and signaling devices mounted to the front, rear and sides. The car has equipped with blinking turn signals to letting information for the other drivers. Sometimes the drivers didn't noticed that the rear flickering light is not blinking. This condition is a major cause of accidents. The study aim to develop the Alternative Rear Flickering Light System. It is designed to turn the brake lights in flashing mode to replace the broken rear flickering signal. At the same time, a blue light indicator is placed on the dashboard to alert the driver. The system uses the Arduino programming to create hardware or programs for vehicles' flickering light. The programming of Arduino has been tested for brake lamp (red color), blinking testing (right and left signal) and alternative flickering (brake lamp blinking). The result has been successful for several attempts the coding on Arduino. This system solves of the main problems encountered for every driver when the rear flickering light is not working. This can also turn the other drivers to be aware of the warning given on the headlights.
\end{abstract}

(C) 2020 The Authors. Published by IICET.

This is an open access article under the CC BY-NC-SA license

(https://creativecommons.org/licenses/by-nc-sa/4.0

\section{Corresponding Author:}

Mastura Ibrahim,

Department of Mechanical Engineering, Politeknik Sultan Mizan Zainal Abidin, Malaysia

Email: mastura.ibrahim@psmza.edu.my

\section{Introduction}

In this modern era, automotive engineering has been one of the biggest field in developing and producing finest and modern technologies. Every engineers are working their best to develop the best vehicle which is fulfil every aspects and demand. Nowadays, a car is a basic need for everyone where it help them to go to a place to another effortlessly. Whether its a sport utility vehicle or a sedan, every production must step up their game equally especially in aspect of safety. Automobile manufactures became more concern with improving car safety and preventing injuries and deaths.

One of the weakness of vehicle is rear flickering lights will burnt or broke at some point. Once upon a time driver relied on hand signals to notify other people on the road of their intention to turn their vehicle in a certain direction. This will increase the risk for the driver and third party to be in an accident because they fail to give information to alert everyone who are in the surrounding. This condition can lead for a higher risk to everyone who is on the road around it and may be involve into an accident (Nguyen-Phuoc, Tran, De 
Gruyter, Kim, \& Su, 2019) A driver must always be alert with their vehicle's condition. However, this particular condition doesn't have a clear indicator if the rear flickering lights aren't working.

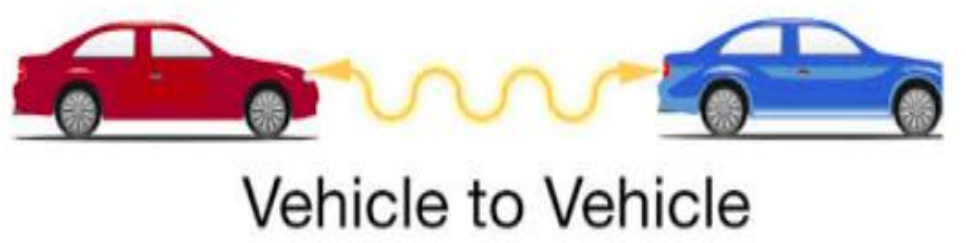

Figure $1<$ V to V Communication (Jamali et al., 2018) >

The objective of study is to develop an Alternative Rear Flickering Lights System. This system will boost a car safety feature because the system itself will alternate any rear flickering lights that is not working to rear brake light automatically. In addition, this will prevent from a situation where other drivers or the surrounding didn't receive any signal from a car where its rear flickering light weren't working.

\section{Method}

\section{Flickering Light System Design}

This system has been developed consist of the main problems encountered for every driver when the back flickering light is not working. Naturally, the driver didn't realize the flickering turn signal is not function. This can also be a case of road accidents and other drivers may be not aware of the warning given on the headlights.

Figure 2 shown how the Arduino work to give an indicator light on control panel is blue color lit and indicates that the signal has been broken. The driver should be alert that the turns signal has been broke and need to turning on the flickering brake light switch. The brake light replacing the broken signal is dimmed when the switch is turned to turn left or right provided by the driver. The other driver must be alert that the blinking of brake lamp is a signal to turns.
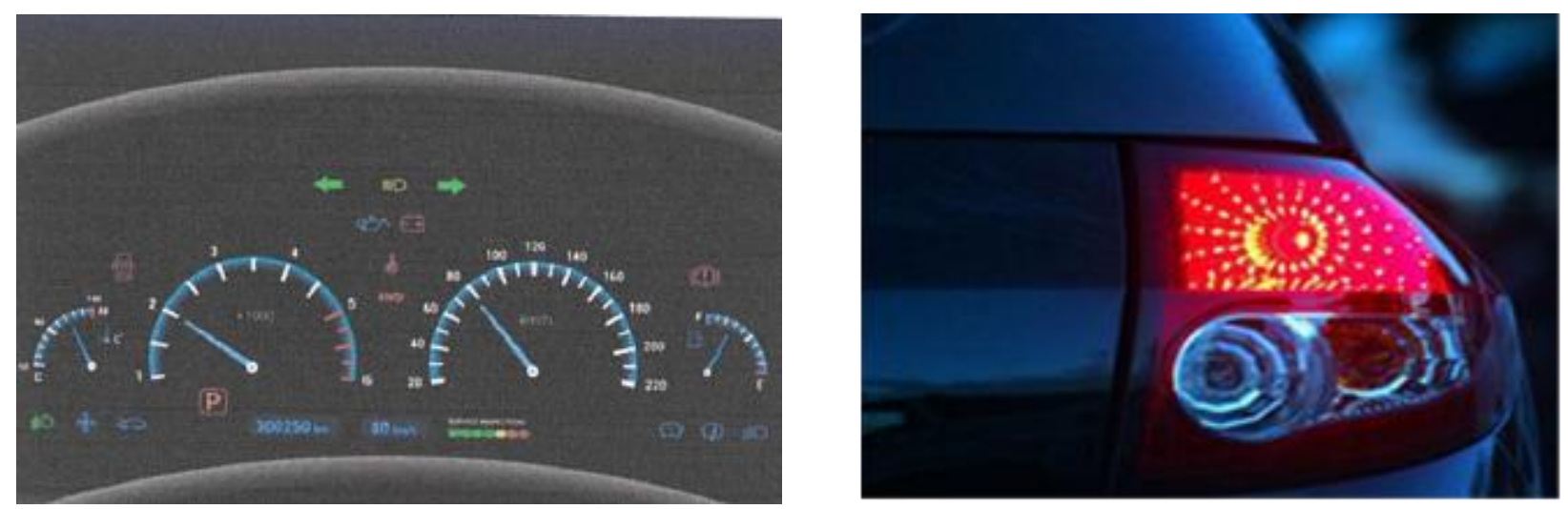

Figure 2 <Indicator Light On the Car Panel and Flickering Brake Light>

Design concept to develop an Alternative Rear Flickering Light System is used Arduino Uno as a parent to a circuit. Figure 3 shown the flow chart to develop of Alternative Rear Flickering Light System. 


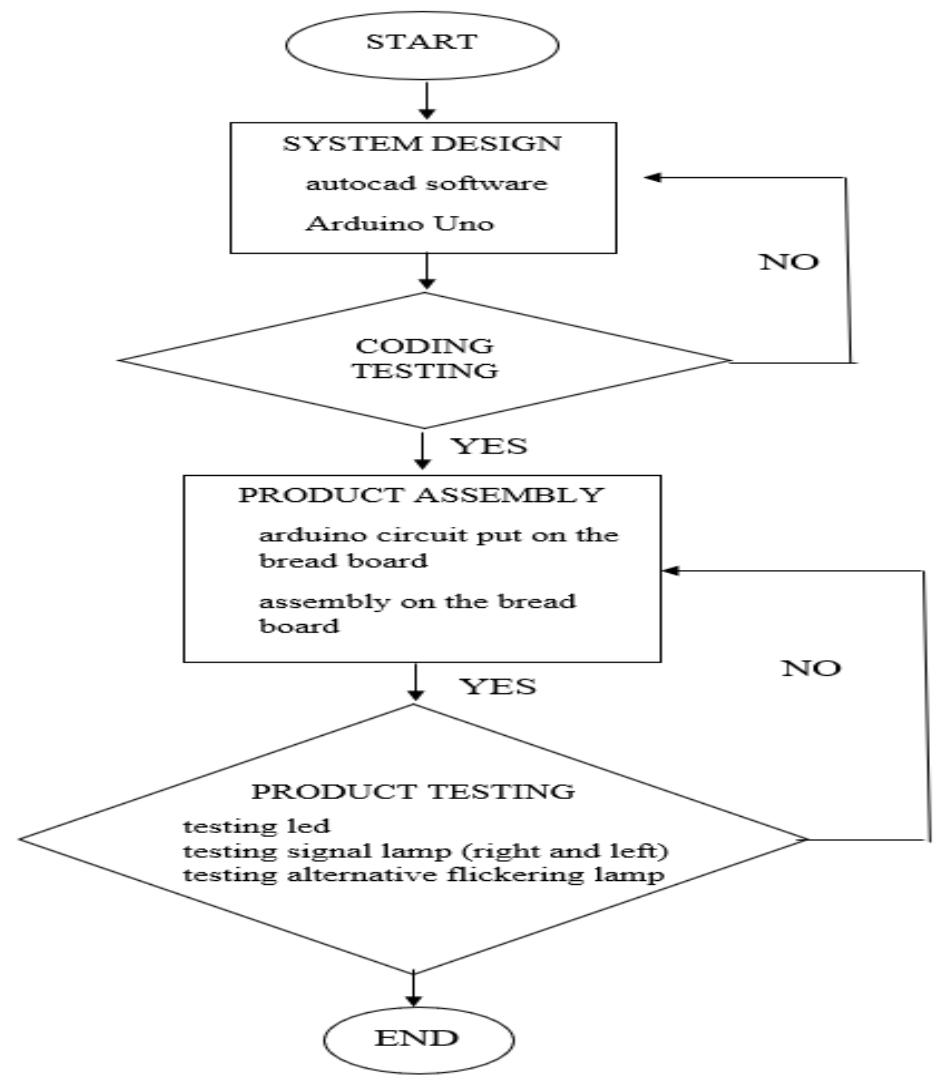

Figure $3<$ The Flowchart Product Development $>$

\section{Arduino Uno in the Flickering Light System Design}

Arduino is an open source platform used for constructing and programming electronic projects. Arduino consists of both physical programmable circuit board as a microcontroller and piece of software or Integrated Development Environment (IDE) that run on the computer , used to write and upload computer code to the physical board (Arduino, 2015). It contain everything needed to support the microcontroller (Mowad, Fathy, \& Hafez, 2014). The Arduino is quite easy to implement control logics on this microcontroller board (Bawa \& Patil, 2013). Figure 4 shown the component has been used to develop the flickering light system.
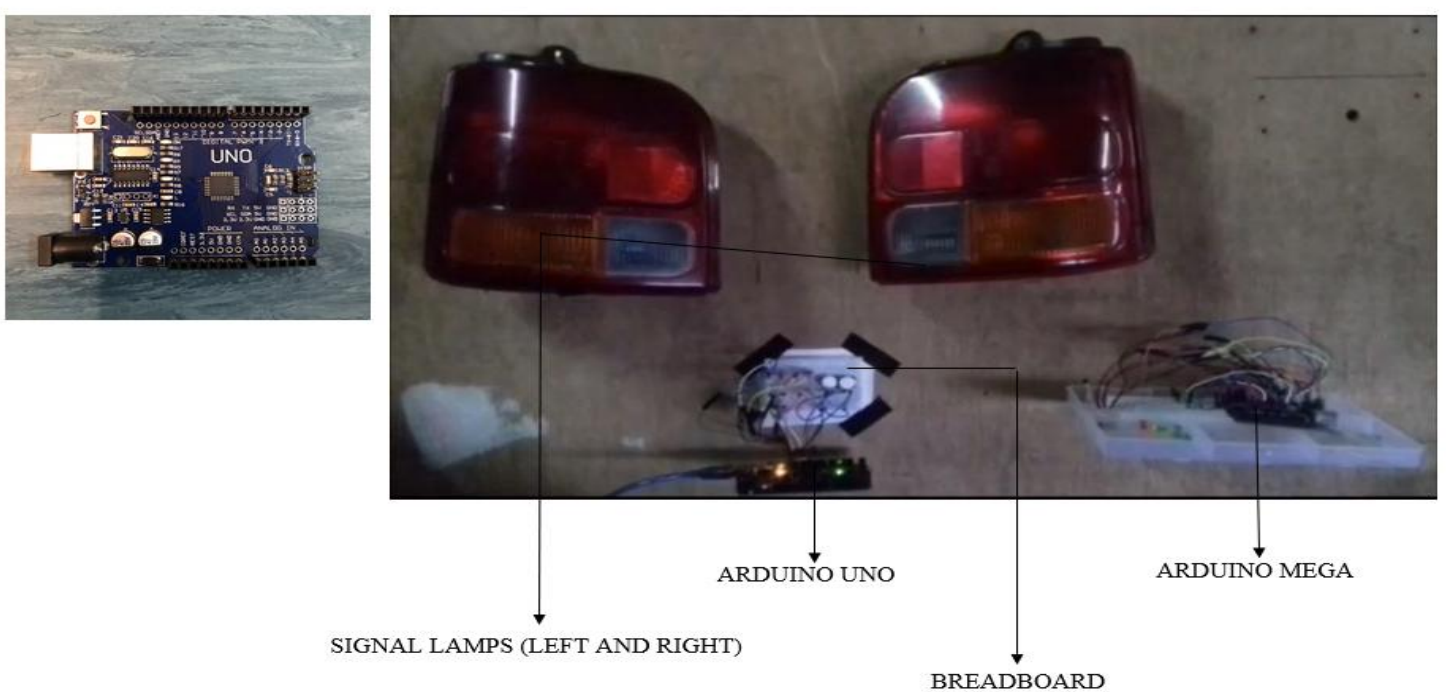

Figure 4 <Arduino Board and Component of Flickering Lamp System> 


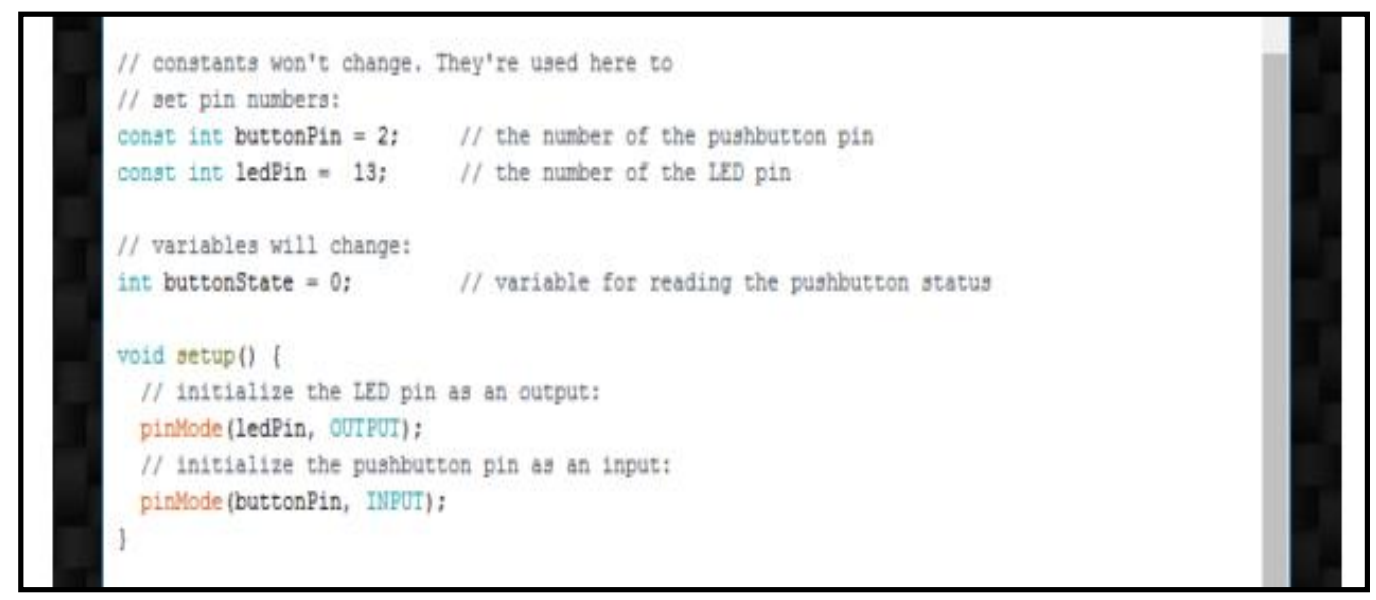

Figure 5 <Programming Code (Badamasi, 2014)>

\section{Results and Discussions}

The testing of programming Arduino depicted in Table 1 for brake lamp (red color), blinking testing (right and left signal) and alternative flickering (brake lamp blinking). Before setup the function, we need to initialize the variables that want to use and assign them because the initial condition of variables and run preliminary code only once (Badamasi, 2014).

Table 1 <The Testing Result of Arduino Programming >

\begin{tabular}{lcc}
\hline Testing & Coding & Result \\
\hline Brake Lamp Testing (Red Color) & Trial 1 & Failed \\
& Frial 2 & Successful \\
Blinking Testing (Right Signal Lamp) & Trial 3 & No Blink \\
& Trail 1 & Blink \\
Blinking testing (Left Signal Lamp) & Trial 2 & No Blink \\
& Trial 1 & Blink \\
Alternative Flickering (Brake Lamp Blinking) & Trial 2 & No Blink \\
& Trial 1 & Blink \\
\hline
\end{tabular}

The system was tested in four situation of blinking lamp. In the first, testing is done on the coding brake lamp as red color. Trial 1 and Trial 2 shown the coding is failed because the Arduino can't read the coding properly. In this situation the code that has to passed to the Arduino failed to turn on the red LED as the brake light. The coding for push button also can't be used to switch on the lights. Trial 3 shown the brake lamp is blinking with the correct coding for brake lamp and push button. The testing for brake lamp was successful.

The second coding testing is done for left and right signal lamp blinking. Trial 1 shown the left signal lamp is no blinking because the coding of LED blink push button LED blink is incorrect. Trial 2 shown the left and right signal lamp successful is blinking with the correct coding.

The last testing was doing to the alternative flickering (brake lamp blinking). The first and second trial was failed, because the coding are used is incorrect. The new coding needed to install in Arduino Uno board. Finally, after the trial 3 , the coding was successful for the alternative of brake lamp is blinking.

\section{Conclusion}

The turn signal is contributes to driver safety and other drivers on the road. When the vehicle will remain drivable, the driver has lose the easiest and safest way to communicate an intentions on the road with other drivers. The Alternative Rear Flickering Light system was developed as an indicator to driver that signal turns 
don't flash as usual. The control panel shows blue light to warn the driver to press the brake light switch. This project recommended to implement the alternative flickering light in real cars to test the effectiveness.

\section{Acknowledgments}

The authors would like to express the deepest appreciation to Dr. Sharifah Nurulhuda for the moral support throughout the research. Sincere gratitude also goes to all my friend and Department of Mechanical Engineering for the support. State the Clinical Relevance of the Findings;

\section{References}

Arduino, S. A. (2015). Arduino. Arduino LLC.

Badamasi, Y. A. (2014). The working principle of an Arduino. Paper presented at the 2014 11th international conference on electronics, computer and computation (ICECCO).

Bawa, D., \& Patil, C. (2013). Fuzzy control based solar tracker using Arduino Uno. International Journal of Engineering and Innovative Technology, 2(12), 179-187.

Jamali, A. A., Rathi, M. K., Memon, A. H., Das, B., Ghanshamdas, \& Shabeena. (2018). Collision Avoidance between Vehicles through LiFi based Communication System. IJCSNS, 18(12), 81.

Mowad, M. A. E.-L., Fathy, A., \& Hafez, A. (2014). Smart home automated control system using android application and microcontroller. International Journal of Scientific \& Engineering Research, 5(5), 935-939.

Nguyen-Phuoc, D. Q., Tran, A. T. P., De Gruyter, C., Kim, I., \& Su, D. N. (2019). Turn signal use among car drivers and motorcyclists at intersections: a case study of Da Nang, Vietnam. Accident Analysis \& Prevention, 128, 25-31. 